\title{
O processo de transição profissional na perspectiva de técnicos de enfermagem que se tornaram enfermeiros
}

The professional transition process from the perspective of nursing technicians who have become nurses

\author{
Proceso de transición profesional en la perspectiva de técnicos de enfermería convertidos en enfermeros
}

Roibison Portela Monteiro ${ }^{1}$, Walnice Jung ${ }^{2}$, Daniele Delacanal Lazzari ${ }^{3}$,

Eliane Regina Pereira do Nascimento ${ }^{4}$, Julcinéia Miguel Dalamaria ${ }^{5}$

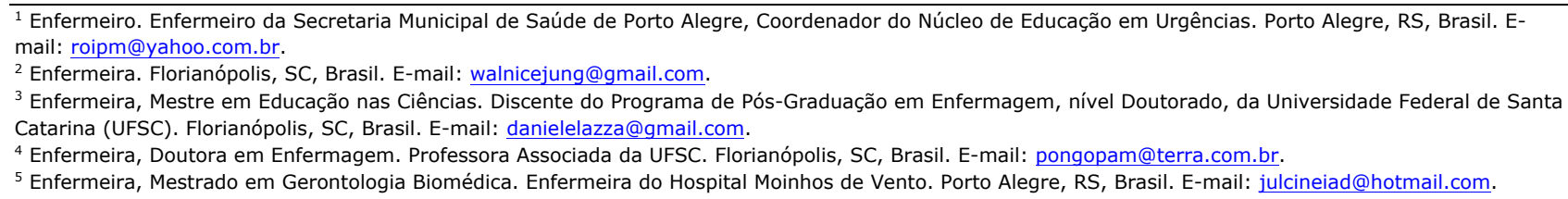

\section{RESUMO}

Estudo descritivo de abordagem qualitativa que visou conhecer os sentimentos vivenciados por enfermeiros com formação em técnico de enfermagem durante a transição de categoria profissional. Os dados foram coletados por meio de entrevista semiestruturada, abordando o trabalho no exercício das duas formações, as mudanças percebidas e interpretadas por meio da técnica de análise de conteúdo, modalidade temática. Os relatos evidenciam que os saberes e as experiências pregressas influenciaram positivamente, mas produziram mudanças pouco significativas na prática profissional. Os participantes expressaram sentimentos de incongruência entre os valores educativos aprendidos na academia e os vivenciados no local de trabalho. Alguns destes profissionais reproduzem comportamentos e ações de chefias estereotipados devido aos modelos internalizados de bons enfermeiros e às expectativas irrealistas. Conclui-se que esta transição é maldefinida, ritualizada, sem caráter inovador ou criativo, correspondendo, por vezes, aos objetivos controladores da instituição e reproduzindo o paradigma mecanicista.

Descritores: Enfermeiros; Educação em Enfermagem; Mobilidade Ocupacional; Recursos Humanos em Saúde; Programas de Graduação em Enfermagem.

\section{ABSTRACT}

Descriptive study of quantitative approach aimed at getting to know the feelings experienced by nurses trained as nursing technicians during their transition of professional category. Data was collected through semi-structured interviews addressing the work done during the course of both training, as well as the changes perceived and interpreted by means of the technique of content and theme analysis. The testimonies show that the knowledge and previous experiences had a positive influence but produced little significant change in professional practice. Participants expressed feelings of incongruity between the educational values learned in school with the experiences faced at the workplace. Some of these professionals reproduce behaviors and actions of stereotyped bosses due to internalized models of good nurses and unrealistic expectations. The conclusion is that this transition is poorly defined, ritualized, without an innovative or creative character, corresponding sometimes to the institution's controlling goals and reproducing the mechanistic paradigm.

Descriptors: Nurses, Male; Education, Nursing; Career Mobility; Health Manpower; Education, Nursing, Diploma Programs.

\section{RESUMEN}

Estudio descriptivo de abordaje cualitativo, objetivando conocer los sentimientos experimentados por enfermeros con formación de técnicos de enfermería durante la transición de categoría profesional. Datos recolectados mediante entrevista semiestructurada, abordando el trabajo en el ejercicio de ambas formaciones, los cambios percibidos, e interpretadas mediante análisis de contenido, modalidad temática. Los testimonios expresaron que los saberes y experiencias pasadas influyeron positivamente, aunque generaron cambios poco significativos en la práctica profesional. Los participantes expresan sentimientos de incongruencia entre los valores educativos aprendidos en la academia respecto de los experimentados en el lugar de trabajo. Algunos profesionales reproducen comportamientos de jefaturas estereotipadas, debido a los modelos internalizados de buenos enfermeros y a las expectativas irreales. Se concluye en que esta transición está mal definida, ritualizada, sin carácter innovador o creativo, correspondiendo a veces a objetivos de control institucionales y reproduciendo el paradigma mecanicista.

Descriptores: Enfermeros; Educación en Enfermería; Movilidad Laboral; Recursos Humanos en Salud; Programas de Graduación en Enfermería. 


\section{INTRODUÇÃO}

A organização e divisão do trabalho em enfermagem no Brasil são sustentadas pela Lei do Exercício Profissional da Enfermagem, Lei n. ${ }^{\circ}$ 7.498/86 e subdivididas em categorias profissionais, sendo elas: enfermeiro, técnico e auxiliar de enfermagem (a última não é mais regulamentada em lei, por isto está em extinção $)^{(1)}$. Esta divisão parcelar do trabalho pressupõe diferentes níveis de formação, um conjunto distinto de atividades caracterizadas pela disciplina e por um grau de hierarquia interna ${ }^{(1-2)}$.

Ao enfermeiro são atribuídos os cuidados de maior complexidade técnica, além da administração das unidades de saúde e das atividades de ensino ${ }^{(1-3)}$, desempenhando um papel que se amplia gradativamente, ao longo da história, exigindo-lhe maiores habilidades e competências na execução de seu trabalho ${ }^{(1-3)}$. Os técnicos e auxiliares exercem atividades de nível médio e de baixa complexidade, planejam e executam ações assistenciais de enfermagem, exceto as privativas do enfermeiro, cabendo-Ihes ainda, participar da equipe de saúde, da programação da assistência, da orientação e supervisão do trabalho em grau auxiliar ${ }^{(2-3)}$.

Ao analisar o crescimento da força de trabalho em enfermagem se constata que, majoritariamente, o número de técnicos de enfermagem (TE) cresceu de forma mais acentuada, devido ao incremento das políticas educacionais de profissionalização na área da saúde ${ }^{(3)}$.

Os técnicos e auxiliares de enfermagem cursam a graduação por esta possibilitar uma diversidade de locus de atuação em múltiplos cenários, espaços e contextos do atendimento à saúde ${ }^{(3-4)}$. Também por ser um curso menos seletivo que outros considerados de maior prestígio social, por permitir a ascensão profissional, por implementar o conhecimento científico e por vislumbrar mudança de status dentro da equipe ${ }^{(3)}$.

As instituições privadas atraem cada vez mais este público, com oferta de bolsas de estudo, com a implantação de unidades escolares na periferia das grandes cidades, facilitando o acesso, oferecendo alguns componentes curriculares na modalidade à distância, ou ministrando as aulas em dias e horários mais flexíveis que favoreçam ao aluno trabalhador ${ }^{(3,5)}$. O profissional ao buscar outra formação dentro da mesma profissão não visa somente melhores salários, pois os proventos dos trabalhadores desta área são menos promissores se comparados com outras profissões da área da saúde ${ }^{(4)}$.
Na sua maioria são acadêmicos que trabalham para subsidiar seus estudos. Esta dinâmica de vida se torna estressante, resulta em baixa produtividade, tanto na escola quanto no trabalho, impõe restrições à vida familiar e social, com tempo escasso para as necessidades básicas, como sono, lazer e estudos ${ }^{(2,4)}$. Isto contraria o discurso humanístico do ensino da graduação, o qual deveria iniciar em sala de aula(4-5).

O termo ascensão profissional está ligado à transição, que num sentido amplo significa qualquer evento que resulte em mudanças nos relacionamentos, crenças, rotinas e adaptação a novos papéis ${ }^{(6)}$. As transições podem ser descritas como transformações que estruturam a experiência pessoal, isto é, situações em que novos papéis demandam novos desempenhos e a familiarização com as novas rotinas, regulamentos, relacionamentos e expectativas do novo cenário ${ }^{(4-5)}$.

Assim, estudar este fenômeno do ponto de vista da profissão se constitui em temática inerente ao questionamento das práticas e dos saberes, por sua relação com as tendências e perspectivas do mercado de trabalho no âmbito da empregabilidade, além de ser um assunto relativo à área da formação do enfermeiro enquanto sujeito crítico/reflexivo no atendimento à saúde integral do ser humano, conforme explicitado nas Diretrizes Curriculares Nacionais do Curso de Graduação em Enfermagem ${ }^{(7-8)}$.

A partir da problemática delimitada propôs-se o presente estudo que foi norteado pela seguinte questão de investigação: Como se caracteriza o processo de transição de Técnicos de Enfermagem graduados em Enfermagem para uma função de enfermeiro na organização em estudo?

Assim, a pesquisa teve como objetivo conhecer os sentimentos vivenciados por enfermeiros com formação em técnico de enfermagem, durante a transição de categoria profissional.

Acredita-se que esta pesquisa pode contribuir para a construção da identidade profissional, elucidar e interpretar os fatores subjacentes ao trabalho de enfermagem implícitos nos serviços desta equipe, tanto da dimensão estrutural e simbólica, tal como a organização e a divisão do trabalho e do mercado de formação de recursos humanos.

\section{MÉTODOS}

Pesquisa descritiva de abordagem qualitativa, desenvolvida em uma instituição hospitalar privada, de grande porte em Porto Alegre - Rio Grande do Sul, nos 
meses de agosto e setembro de 2011. Justifica-se a escolha do local pelo fato de ser uma instituição que incentiva a formação e ascensão funcional dos profissionais, além de possuir o selo de acreditação em qualidade na assistência médico-hospitalar pela Joint Commission International.

Participaram do estudo enfermeiros que tiveram experiência anterior na área atuando sem formação superior, sendo estes selecionados de acordo com os seguintes critérios de inclusão: ser enfermeiro graduado há pelo menos um ano e ter exercido função como técnico ou auxiliar de enfermagem. Foram excluídos aqueles em gozo de férias, folga ou licença saúde no momento da coleta de dados. Entrevistaram-se oito enfermeiros de turnos e setores diversos, de ambos os sexos, que demonstraram interesse em participar do estudo e que atendiam aos critérios de inclusão. 0 número de participantes foi delimitado pelo critério de saturação dos dados, ou seja, a reincidência dos conteúdos emergentes nos discursos ${ }^{(9)}$.

A coleta de dados foi realizada por meio de entrevista individual, utilizando-se um roteiro semiestruturado que contemplou três questões centrais: a trajetória profissional; o trabalho desenvolvido no exercício das duas formações profissionais; e, as diferenças percebidas por estes profissionais antes e após a transição de categoria.

As entrevistas ocorreram durante o intervalo no horário de trabalho, conforme solicitação dos entrevistados, em sala reservada, oferecida pela instituição. Os participantes foram informados sobre os objetivos deste estudo e após os esclarecimentos, assinaram o Termo de Consentimento Livre e Esclarecido (TCLE). Para a garantia do anonimato foram identificados pela letra E (Enfermeiro), seguida pelo número correspondente à ordem de realização das entrevistas (E1, E2, E3, etc.).

A pesquisa foi realizada após aprovação do Comitê de Ética do Instituto de Educação e Pesquisa do hospital em estudo, sob o protocolo n. ${ }^{\circ} 2007 / 35$, respeitando os preceitos éticos preconizados pelo Conselho Nacional de Saúde.

A técnica de Análise de Conteúdo, modalidade temática, foi aplicada ao material empírico após a gravação e transcrição literal de cada entrevista. Este processo de análise é composto por três fases: 1) a de pré-análise (leitura flutuante $e$, em um segundo momento, em profundidade de cada um dos relatos e formulação de hipóteses); 2) a de exploração do material (codificação e definição de categorias) e transformação dos dados brutos para o núcleo de compreensão do texto; e, 3) a fase do tratamento dos resultados e de sua interpretação (processo de reflexão) ${ }^{(10)}$.

Os resultados foram agrupados por meio da observação de suas similaridades e regularidades, constituindo três categorias: 1) a ascensão profissional: sentimentos manifestos à função anterior; 2) trocando os papéis: a trajetória percorrida; e, 3) assumindo o novo papel e novas competências: ser enfermeiro.

\section{RESULTADOS}

Participaram deste estudo oito enfermeiros, sete do sexo feminino e um do sexo masculino; o tempo de trabalho na enfermagem como auxiliar ou técnico foi de 13 a sete anos; o tempo de formação como enfermeiro foi de um a seis anos.

Desta pesquisa emergiram três categorias distintas, que serão descritas a seguir.

\section{A ascensão profissional: sentimentos manifestos à função anterior}

Ao serem questionados sobre os sentimentos vivenciados após a ascensão profissional, os sujeitos expressaram ansiedade, o medo de errar, a não adaptação à nova função e a crença de que a oportunidade de permanecer no emprego dependia de aceitação profissional. São relatos obtidos:

Senti dúvida sobre continuar trabalhando aqui. Seria meu desempenho a contento? Medo da negatividade, das relações de poder ou rejeição dos colegas. (E1)

Fiquei ansiosa e preocupada, pois exerceria um papel diferente do qual estava acostumada. Tomaria decisões e gerenciaria a equipe. Isto gerou o medo de errar. A expectativa de implementar melhorias no setor e não aceitarem. (E2)

Gerou preocupação e ansiedade. Como já era funcionária do hospital imaginava se conseguiria a promoção e se seria realmente capaz de assumi-la. (E3)

Senti-me orgulhosa e satisfeita ao me formar. Foi a chance de superar a falta de autonomia do TE e conquistar maior poder de decisão. Não seria mais tão explorada, não executaria o trabalho manual e conquistaria uma ascensão salarial e intelectual também. Além de "status" na profissão e na empresa. (E5)

Vislumbrei a chance de meu trabalho aparecer, despontar. Pois o trabalho do TE não tem tanta importância igual ao do enfermeiro. É o técnico que 
realiza o trabalho sujo. Claro, tem qualidade, mas é de menor importância. (E6)

O trabalho do TE está fortemente associado a uma dimensão eminentemente do domínio do fazer e, portanto, mecânica, conforme mencionam os entrevistados:

Havia a alegria da conquista. O serviço do auxiliar de enfermagem é uma repetição de tarefas diárias, o trabalho não aparece no tratamento do paciente. Há uma falta de autonomia para resolver os problemas mais simples dos pacientes e isto causa um sentimento de impotência. (E2)

Estava angustiada, mas orgulhosa por concluir a graduação. Senti-me emancipada e mais qualificada, pois deixaria de desenvolver tarefas desagradáveis. Enquanto técnica atuava em um espaço restrito e exercia um trabalho adestrado, um mero executor de tarefas. Agora mandaria e daria ordens e não mais receberia ordens autoritárias das chefias. (E6)

Foi uma vantagem a mais, já ter trabalhado como TE. (E5)

No entanto, é evidente que não há um contorno preciso nos limites de suas atividades, conforme ilustram as narrativas que se seguem:

Considero o TE um microenfermeiro. Executamos as tarefas e técnicas similares. Mas só o enfermeiro pode comandar a equipe e prescrever. (E3)

A experiência profissional anterior como TE me garantiu o bom desempenho inicial como enfermeira. O trabalho técnico já conhecia, pois não há diferença na execução dos procedimentos que os enfermeiros realizam. (E5)

\section{Trocando os papéis: a trajetória percorrida}

Os próximos relatos demonstram como o conhecimento adquirido, enquanto técnico, influenciou o processo de transição desses profissionais:

O trabalho como TE e a destreza manual adquirida facilitaram a mudança de papel. Percebi isto enquanto observava os colegas que não foram técnicos: a execução das técnicas era tranquila para mim e fonte de ansiedade para os outros que não tiveram a mesma trajetória. (E6)

Tecnicamente me sentia mais preparado, por já vivenciar as técnicas e os procedimentos diariamente na assistência. Entramos mais preparados na profissão de enfermeiros em relação aos outros colegas que não foram técnicos. (E8)

$\mathrm{Na}$ instituição em estudo, os sujeitos observam que já conhecer a rotina da unidade é vantagem no momento da transição, conforme os discursos abaixo:

A maior facilidade foi por trabalhar neste hospital há oito anos, por conhecer as rotinas, a dinâmica do trabalho, a política, os valores. (E2)

Considero como facilidade já conhecer a instituição, as pessoas, as rotinas, a equipe médica, isso facilitou bastante. (E4)

As falas seguintes demonstram que esses profissionais apresentaram dificuldades para se desligar da função de TE e, ainda, a questão do afastamento do enfermeiro da ação cuidadora direta:

Sem perceber, estava na farmácia buscando medicação, trocando uma fralda ou desenvolvendo atividades pertinentes à rotina do técnico. Precisei me organizar, senão não desenvolvia as atividades sob minha responsabilidade. (E1)

Preferia desenvolver as atividades mais simples a pedir a alguém. Se eu avaliava um curativo e ele estava sujo, eu mesma o trocava. Envolvia-me tanto com as atividades do TE que acabava atrasando minhas tarefas de enfermeira. (E2)

Desligar-me da função de TE levou algum tempo. Comecei a perceber a mudança após dois anos, quando me vi mais envolvida com a parte administrativa e mais distante do cuidado direto com os pacientes. (E3)

Outro obstáculo apontado pelos sujeitos diz respeito à dificuldade em administrar:

Tive dificuldades em liderar, em ser responsável por uma equipe com tantos funcionários. O ritmo agitado e rápido do setor, os pacientes com várias intercorrências. (E2) Senti muito medo e insegurança, principalmente na questão da liderança e do gerenciamento das pessoas e da unidade. (E4)

A faculdade nos ofertou pouco conteúdo sobre liderança e poucas oportunidades para desenvolvê-la, organizar um grupo, enfim. (E2)

o gerenciamento só foi possível vivenciar no último estágio, mas por tempo insuficiente. Muitas vezes como 
"sombra" de enfermeiros da unidade, observando. Minha formação não me ajudou nesse aspecto. (E2)

Os participantes mencionam um aumento de responsabilidades subjacente à transição de função:

Foi complicado porque nos primeiros meses é pouco tempo para a elevada carga de responsabilidade e de trabalho que nos é destinada a cumprir. (E4)

\section{Assumindo o novo papel e novas competências: ser enfermeiro}

Esta categoria emergiu das falas dos sujeitos se referindo ao relacionamento com a instituição e aos interpessoais com a equipe, momento em que mencionam o apoio e o reconhecimento pelo trabalho realizado como enfermeiros e que a sua atuação como TE facilitou o processo de transição. Conforme apontam os depoimentos:

Seis meses antes da minha formatura, fui alocada em outro setor. No início, sofri bastante, mas reconheço que aprendi muito. Vivi novas situações e compreendi o funcionamento do hospital de maneira ampla. Valeu a pena. (E1)

Foi gratificante trabalhar oito anos em uma instituição como TE. Ao me formar e ser promovida percebi o quanto valorizaram meu trabalho e minha formação. (E2)

Foi uma vantagem iniciar uma nova função na instituição em que eu já trabalhava [...] o hospital me apoiou e me deu o incentivo necessário. (E5)

Os relatos a seguir apontam para a aceitação e a acolhida, ainda que não imediata, dos sujeitos deste estudo por outros enfermeiros:

Fui bem recebida, claro que às vezes havia críticas construtivas tais como, o momento de agir, ou quando adotava uma postura de TE. (E3)

Percebi certo distanciamento no início. Levou algum tempo para cativar a confiança. Acredito que quem me acolheu não estava preparado para a reconstrução desta relação. Existe sim, uma diferenciação. (E4)

Neste hospital existem enfermeiras há muito tempo na função. Não é fácil a chegada de um novo membro ao grupo. Mas, quando começam a te conhecer, as relações melhoram. (E6)
Observando os seguintes discursos, percebem-se as relações de apoio:

As enfermeiras que vivenciaram o processo me apoiaram até mesmo as mais antigas, sempre se colocando à disposição para ajudar. (E5)

[...] depende da pessoa, da forma de agir. Tem que ter humildade. Muitas vezes pedi ajuda a outras enfermeiras para resolver alguma situação na minha unidade ou com os funcionários, e a recebi, prontamente. (E6)

Em relação às competências técnicas, um dos participantes destacou a importância de dominar os temas técnicos desenvolvidos no setor de trabalho para garantir o sucesso da transição, conforme a seguinte verbalização:

É essencial ter competência e conhecimento técnico porque corremos o risco de tomar decisões erradas e até porque os funcionários nos pedem apoio em diversas questões técnicas às quais temos que responder e saber fazer. (E2)

Por sua vez, E3 e E6, afirmaram sentir dificuldades por não dominarem os conteúdos técnicos desenvolvidos nas áreas que estão a gerir, conforme suas falas:

Tecnicamente não conheço tudo, porque o meu histórico profissional foi sempre na área de atenção básica. (E3)

Tenho muitas lacunas em termos de liderança. No curso recebemos conteúdos teóricos sobre administração de Enfermagem, mas no estágio não vi como o TE participa do processo administrativo ativamente. (E6)

De forma a dissipar estas carências, os participantes buscaram ativamente informação, individualmente ou recorrendo aos colegas de trabalho, para desenvolver novas competências que Ihes permitiram desempenhar devidamente as suas funções, tal como se pode verificar no discurso de E7:

Procurei as enfermeiras mais antigas para compartilhar dificuldades na gestão e dediquei mais à leitura e ao estudo de temas relacionados à liderança. (E7)

Os enfermeiros relatam como ficaram as relações com os antigos colegas TE e auxiliares, agora em diferentes níveis hierárquicos: 
Mudei de postura. Não era mais a mesma profissional. Senti-me mal, mas tive que mudar. Se misturasse as relações com meus amigos $T E$, não conseguiria liderar. Tenho dificuldade em definir os limites de autonomia. (...) algumas questões não me são claras, se posso definir sozinha, sem a diretoria. (E1)

Começar a chefiar uma equipe em que todos eram teus colegas é complicado. Tens que delegar, fazer cobranças, tomar decisões significativas, controlar, avaliar as atividades desenvolvidas pelos membros e alguns dos antigos colegas de profissão não aceitam esta nova relação. (E8)

Os sujeitos expressam os obstáculos referentes aos relacionamentos interpessoais, transcorrido o período inicial de adaptação:

Era algo que eu precisava superar. Com o tempo, passou. Hoje é tranquilo. (E1)

Se soubermos lidar com elas, essas relações nos fazem amadurecer. (E4)

A questão da idade dos membros da equipe, com pessoas mais velhas e/ou mais experientes, sob a coordenação desses enfermeiros também surgiu no discurso de dois participantes:

A minha equipe têm pessoas mais velhas que eu, com maior tempo na empresa. Senti desconfortável em liderá-los, pois percebi certo receio inicial quanto a minha adaptação e pouca aceitação ao meu cargo de enfermeira. (E1)

Têm pessoas que trabalham aqui há 15-20 anos, que são os mais velhos. E sou mais jovem e de outra equipe.

\section{DISCUSSÃO}

Verifica-se que as expectativas constituídas por um iniciante transitando entre funções levam consigo, além dos conhecimentos e aptidões, os valores e as motivações para a implementação de mudanças na instituição e às pessoas que nela trabalham ${ }^{(7,10)}$.

Uma transição bem-sucedida requer que o indivíduo seja capaz de "separar-se" do seu papel anterior ${ }^{(11)}$. Os trabalhadores ainda aderidos à função pregressa tendem a tê-la como uma referência e comparam-na com a atual, o que pode promover dificuldades na exploração do novo papel ${ }^{(13)}$. Esta ruptura se traduz na mobilidade e flexibilidade desses sujeitos no meio organizacional ${ }^{(11-14)}$.
Também permite a libertação de vícios de carreira e da influência de experiências anteriores, permitindo trocas, mudança na percepção e crescimento profissional ${ }^{(11)}$.

As expectativas e o sentimento de insegurança são comuns a este momento, pois, o recém-formado se depara com um mercado de trabalho que exigirá conhecimento teórico, agilidade, criatividade e capacidade para a tomada de decisões que dependerão do seu conhecimento e da sua maturidade ${ }^{(9,12)}$. De acordo com alguns estudos, o cuidar no contexto da Enfermagem pode causar ansiedade. Seria relevante, por parte dos professores e enfermeiros de campo, o fortalecimento emocional e o autoconhecimento dos estudantes sobre os medos e a ansiedade, próprios do cuidar de si e dos outros ${ }^{(7,15)}$.

Pesquisas $^{(16-18)}$ apontam que os TE, por executarem procedimentos manuais, repetitivos, vazios de conteúdo científico, de contato rotineiro com a "sujidade", desvalorizados em relação ao trabalho intelectual, consideram as suas atividades destituídas de valor, e esta percepção aliena esse trabalhador ${ }^{(7,12)}$.

A experiência profissional aparece com destaque nos depoimentos dos sujeitos em estudo, que tendem a valorizá-la como um bom desempenho, com valor maior ao da graduação ${ }^{(17-18)}$. Expressam assim uma compreensão de que a formação profissional está acabada e definitiva(12). Essas concepções sobre competências e valores profissionais sustentam a hierarquia e os baixos níveis salariais da enfermagem, ditando assim os postos de trabalho mais valorizados nesse aspecto, enquanto que o trabalho do $T E$, por sua vez, se vê destituído de valor científico e sem prestígio social no processo terapêutico ${ }^{(8,18)}$.

Esta divisão técnica e social de papéis reforça a manutenção de uma elite que implementa e de outra classe que executa as ações de enfermagem, sustentando a relação crônica de subordinação às estruturas de poder na saúde que se desdobra em trabalhos parcelares, de caráter manual e com reduzido valor social da profissão ${ }^{(12,18)}$.

Os discursos expressos reafirmam que o trabalho administrativo do enfermeiro é análogo à burguesia, ao status da classe dominante e isto denota um traço cultural próprio da categoria, sendo o TE hierarquicamente subordinado, com pouca autonomia na performance de seu trabalho e pode ser identificada como parte da classe proletária, independentemente da condição de ser produtiva ou não ${ }^{(11,17)}$. Como resultado deste parcelamento de tarefas que gera uma polarização 
do trabalho do enfermeiro e do TE, a equipe de enfermagem perde a visão do todo na unidade de trabalho ${ }^{(17)}$.

A organização atual dos serviços de saúde conduz o enfermeiro a realizar tarefas de controle, com modelo de gerência baseada nos princípios tayloristas, tais como supervisão de pessoal, não no sentido educativo, mas na cobrança imediata do que deve ser realizado na prestação da assistência, dando-lhe a falsa ideia de que tais tarefas compreendem as funções de planejamento e coordenação $^{(11,18)}$.

$\mathrm{Na}$ formação do TE há maior ênfase na dimensão técnica, o que possibilita pouco crescimento interno do profissional $^{(5)}$. O baixo prestígio somado à percepção de que executa um cuidado automatizado associado à racionalidade técnica afastam ainda mais o técnico da visão de que coopera multidisciplinarmente com a sua equipe e no processo terapêutico ${ }^{(5,17)}$.

Também não vislumbra o reconhecimento de seu desempenho ou incentivos (recompensas financeiras, ascensão profissional, promoções de cargos, premiações, bônus) ${ }^{(13)}$. Não denota um gostar daquilo que faz e ter satisfação no desempenho de um trabalho importante, pois o objeto de trabalho é o cuidado ao ser humano(7,17). Esta identidade profissional assim compreendida e vivida terá por consequência um profissional provavelmente delegando as atividades que pensa poder dispensar aos técnicos e reproduz, ele mesmo, este tipo de comportamento hierárquico com a equipe que liderará(18). Incorpora assim, a simbologia de quem decide é mais competente do que aquele que executa ${ }^{(18)}$.

Estes profissionais também não percebem que a diferenciação do saber é contínua, que surgem cotidianamente novas tarefas a serem realizadas, novas formas de cuidar e tecnologias inovadoras ${ }^{(12,17)}$. Desta forma, os territórios profissionais são fluidos e as fronteiras do trabalho em constante redefinição(5). O saber tem origem na experiência, mas não depende unicamente dela ${ }^{(7)}$. Somente através da aquisição de competências que implicam em vários tipos de saber é que se permite recorrer a conhecimentos, métodos e técnicas, consolidando vivências e situações no contexto da prática profissional ${ }^{(10)}$.

$\mathrm{Na}$ formação do enfermeiro há maior ênfase na dimensão técnica, aos aspectos pedagógicos e à assistência emergencial e curativa, o que possibilita pouco crescimento interno do profissional ${ }^{(4,7)}$. Deste modo, isso não os auxilia no desenvolvimento da consciência e na capacidade de reflexão, competências úteis à sua futura profissão(4).

Também é considerado como um facilitador na mudança de papéis o conhecimento prévio das rotinas da empresa, ao contrário de outros estudos(7), em que enfermeiros relataram, inclusive, a necessidade de deixar de trabalhar na instituição devido a problemas de adaptação e à aceitação pela mudança de papéis ${ }^{(5)}$. Há a necessidade de desconstruir uma vivência para depois se movimentar em outra realidade ${ }^{(7,12)}$. Abandonar um papel não é um processo instantâneo, envolve tempo para assimilação e adaptação, e o novo contexto irá se sobrepor à identidade anterior ${ }^{(5)}$.

Concernente à administração, questiona-se o processo de ensino da liderança na graduação em enfermagem, o que repercute na sua prática profissional ${ }^{(10-11)}$. Alguns autores identificaram que os enfermeiros recém-formados são, em geral, prontamente absorvidos em postos de trabalho, sobretudo, na área hospitalar, porém nem sempre assumem postos de liderança(5). Esta capacidade precisa ser aprimorada gradativamente ao longo da vivência acadêmica, sendo indispensável o cultivo de características, tais como a comunicação, o comprometimento e o saber trabalhar em equipe ${ }^{(11-12)}$.

Analisando o relato dos sujeitos, percebe-se a necessidade de revisão nos processos de ensino/aprendizagem que possibilitem o desenvolvimento de habilidades inerentes à função do enfermeiro, oferecendo aos acadêmicos vivenciarem situações práticas relacionadas à liderança e às atividades administrativas. Apesar de existir pouca investigação, um tutor como uma figura de apoio para os enfermeiros recém-chegados, designado pela chefia direta, pode se constituir em uma prática facilitadora desta adaptação(13). Alguns autores assumem que este parece ser um método adequado ao desenvolvimento de competências de um gestor iniciante ${ }^{(13-14)}$.

Esta estratégia proporciona suporte afetivo e emocional, informação acerca da organização e apoio em nível técnico(13). Todavia, esta forma de integração apresenta alguns riscos, pois pode constituir-se em uma dependência entre o tutor e o iniciante, restringindo o desenvolvimento deste ${ }^{(14)}$. O tutor pode ser tendencioso ao orientar o recém-chegado, imprimindo características do seu próprio trabalho e os conselhos podem não ser os mais adequados ${ }^{(13)}$. De forma a minimizar estes riscos, é essencial eleger um tutor com elevadas competências 
sociais, sem sobrecarga de trabalho, de forma a poder dedicar tempo ao iniciante ${ }^{(13)}$.

Quando se integram a um novo contexto de trabalho, os indivíduos procuram "fazer-sentido" no novo meio em que se encontram ${ }^{(7)}$. Surge então a necessidade em conhecerem e compreenderem a sua nova função e tornarem-se o mais rapidamente possível um membro efetivo e funcional na recente situação profissional ${ }^{(15)}$. Isto parece incentivar os novos colaboradores a procurarem ativamente informação acerca da função. E os membros que já se encontram integrados na organização são essenciais neste $\operatorname{processo}^{(7)}$.

Os resultados de alguns estudos apontam a importância das relações criadas na organização para o sucesso da transição para uma função de gestão, o que é consistente com os resultados desta investigação, tendo em conta que os elos interpessoais foram o tema mais mencionado por esses enfermeiros ${ }^{(7,15)}$. Das falas dos entrevistados, percebe-se a incorporação de elementos ideológicos que reportam a lealdade à instituição, ao reconhecimento, ao engajamento, o pertencimento ao local de trabalho e a valorização do ser humano.

As relações interpessoais têm conexão íntima com o trabalho e colaboram para o sucesso nas atividades realizadas em um grupo e são tão ou mais importantes do que a qualificação individual para as tarefas ${ }^{(10)}$. Quando as necessidades não são satisfeitas, ou questiona-se a sua capacidade, o indivíduo gera algumas impressões desagradáveis, que se tornam emoções como raiva, medo, insegurança e inveja ${ }^{(13)}$.

Imagens de como os pares de trabalho consideram seu desempenho são importantes na autopercepção enquanto profissional ${ }^{(7)}$. Aqueles que conscientemente não se encaixam na imagem ou modelo mental da equipe são rotulados de inadequados ${ }^{(7,12)}$. Em detrimento deste fenômeno, alguns profissionais realizam os seus procedimentos de forma preferencial e assumem crenças e comportamentos da organização como tolerância à rejeição ${ }^{(11,18)}$.

Apesar desta pressão do grupo, os iniciantes não devem perder seus valores profissionais, e sim, procurar a criação e manutenção de ambientes positivos para a prática de enfermagem, que gerem contratos estáveis, com salário proporcional à experiência, formação e nível de responsabilidade ${ }^{(10)}$. Esta pode ser uma explicação para as respostas relatadas pelos sujeitos. As mudanças podem trazer dificuldades nos relacionamentos, já que como enfermeiros foi preciso adotar novas posturas profissionais, que podem, ou não, ser aceitas pelo grupo.
O indivíduo adquire as competências sociais e os conhecimentos necessários à medida que assume o seu papel organizacional, em uma nova função(12). Pela análise do tema - Competências - verifica-se que três participantes deste estudo (E2, E3 e E6) admitiram manifestar a carência de diversos tipos de competências técnicas, de liderança e gestão de equipes. A competência profissional tem sido definida como algo que "permite agir e/ou resolver problemas profissionais de forma satisfatória em um determinado contexto, mobilizando diferentes capacidades" ${ }^{\prime(6,14)}$. Assim, entende-se que as competências são contextualizadas, e as condições e o ambiente de trabalho constituem uma forte influência na sua expressão, podendo ser favoráveis, ou não, à aquisição das mesmas ${ }^{(6)}$.

É fundamental investir no desenvolvimento de competências básicas de gestão tais como, gestão de conflitos, negociação, resolução de conflitos, liderança e avaliação de desempenho(15). Isto pode evitar transições malsucedidas, que têm custos elevados para as organizações ${ }^{(7)}$. A formação pode ser essencial para estes novos gestores, no entanto, assume-se também que "aprender a ser gestor" envolve uma aprendizagem experiencial, o que significa que exige um conhecimento que apenas pode ser criado através do exercício da própria função ${ }^{(14)}$.

A transição feita de forma gradual e progressiva pode ser uma das estratégias da organização para permitir uma melhor adaptação à aprendizagem das novas tarefas ${ }^{(7)}$. Quando um colaborador transita para a função de gestão de uma equipe, adquire um novo status que envolve mais poder ${ }^{(16)}$. Neste sentido, além de preparar o colaborador para assumir uma nova função, prepara-se, concomitantemente, os membros da equipe para essa transição, de modo a evitar resistências e ressentimentos por não ter sido um deles o promovido/escolhido ${ }^{(16-17)}$.

O novo gestor também deve ter uma formalização exata do seu papel atual perante a equipe, a definição clara do papel que assume pela primeira vez na gestão, para permitir que se constituam expectativas realistas relativas à sua nova função(17-18).

A existência de equipes constituídas por colaboradores de diferentes idades implica em diferentes valores, atitudes, e objetivos perante o trabalho, entre seus vários membros ${ }^{(17)}$. Tais diferenças podem conduzir à existência de conflitos no seio do grupo, o que os induz a se sentirem mais aptos para a função de gestão(18). 
É de ímpar relevância que o acadêmico compreenda os dilemas e as ambiguidades da própria profissão, permanecendo atento à especificidade do trabalho da enfermagem, além de desenvolver noção de seus limites, ao programar ações de cuidado ${ }^{(14,18)}$.

\section{CONCLUSÃO}

Este estudo evidenciou que ser trabalhador na área de saúde antes da graduação produz mudança pouco significativa na prática profissional; além de revelar uma transição mal definida e ritualizada. É um período caracterizado por um rápido autodesenvolvimento, com sentimentos de inadequação, alta ansiedade e incongruência entre os valores educativos aprendidos e internalizados na academia, com os vivenciados no local de trabalho.

A experiência anterior como TE reproduz o paradigma mecanicista, sem caráter inovador ou criativo na transição de função, mantendo a ênfase na intervenção técnica, sem vistas às questões de ordem emocional, coletiva e educacional. A visão de ser humano, nesta perspectiva, perde a sua integridade, sua consciência sociocultural. Este desvio da ação cuidadora se insere em um processo de alienação, perda de autonomia no plano do saber e espaço profissional do enfermeiro.

O profissional enfermeiro, mesmo com vivência na área, continua a atuar de forma acrítica e passiva, correspondendo, na maioria das vezes, aos objetivos controladores da instituição. O conhecimento prévio da instituição e das habilidades manuais no desempenho de procedimentos técnico/assistenciais, adquiridos no ofício de técnico, é um elemento facilitador no início da função de enfermeiro.

\section{REFERÊNCIAS}

1. Conselho Federal de Enfermagem (BR). Lei n.7498/86, de 25 de junho de 1986 . Dispõe sobre a regulamentação do exercício da Enfermagem e dá outras providências. [Acesso em: 23 Jun 2014]. Disponível em: http://www.cofen.gov.br/lei-n-749886de-25-de-junho-de-1986_4161.html.

2. Fontana RT, Brigo L. Estudar e trabalhar: percepções de técnicos de enfermagem sobre esta escolha. Esc Anna Nery Rev Enferm. 2012;16(1):128-33.

3. Costa MLAS, Merighi MAB, Jesus MC. Ser enfermeiro tendo sido estudante-trabalhador de enfermagem: um enfoque da fenomenologia social. Acta paul enferm. 2008;21(1):17-23.

4. Colenci R, Berti HW. Formação profissional e inserção no mercado de trabalho: percepções de egressos de graduação em enfermagem. Rev Esc Enferm USP. 2012;46(1):158-66.

5. Patrician PA, Oliver D, Miltner RS, Dawson M, Ladner KA. Nurturing charge nurses for future leadership roles. J nurs adm. 2012;42(10):461-6.

6. Barbosa TLA, Gomes LMX, Reis TC, Leite MTS. Expectativas e percepções dos estudantes do curso técnico em enfermagem
Há a necessidade de maior orientação e de implementação das práticas de socialização que valorizem as relações interpessoais e estimulem as competências essenciais ao desempenho da nova função, como também o aumento gradual da carga de trabalho, no sentido de aumentar a confiança do iniciante e facilitar a sua independência.

Há dificuldade dos profissionais em se desligarem da antiga função. Ocorre a troca de papéis, mas não a troca de alguns valores ou significados. Uma ambiguidade, pois o subordinado passa a reproduzir comportamentos e ações de chefias estereotipadas, devido aos modelos internalizados de "bons enfermeiros" e a expectativas irrealistas.

As instituições de ensino superior por outro lado, em sua práxis educativa, além de privilegiarem o currículo escolar formalmente estabelecido, também precisam considerar a aprendizagem pela experiência (currículo oculto); atentar para as características individuais dos discentes, pois a identidade profissional de seus acadêmicos é vivida e construída por experiências incorporadas e a partir de outras vivências.

Sugere-se, para investigações futuras, o estudo das variáveis causais subjacentes a este fenômeno, com particular destaque para a qualificação real do enfermeiro, em especial a qualificação tácita, oriunda das experiências de trabalho e das relações sociais. Porque a qualificação real dos trabalhadores é muito mais difícil de ser observada e constitui-se mais no "saber/ser" do que no "saber/fazer". O sistema formador precisa se ater às competências subjetivas ao formalizar a qualificação real deste profissional.

com relação ao mercado de trabalho. Texto \& contexto enferm. 2011;20(n. esp.):45-1.

7. Sprandel LIS, Helena Heidtmann Vaghetti HH. Valorização e motivação de enfermeiros na perspectiva da humanização do trabalho nos hospitais. Rev eletrônica enferm. [Internet]. 2012 [Acesso em: 05 Mai 2013];14(4):794-802. Disponível em: http://www.revistas.ufg.br/index.php/fen/article/view/16100/13 343.

8. Ministério da Educação (Brasil). Resolução CNE/CES nº.3, de 7 de novembro de 2001. Diretrizes Curriculares Nacionais do Curso de Graduação em Enfermagem. Diário Oficial da União 2001; Seção 1.

9. Fontanella BJB, Ricas J, Turato ER. Amostragem por saturação em pesquisas qualitativas em saúde: contribuições teóricas. Cad saúde pública. $2008 ; 24(1): 17-27$.

10. Bardin L. Análise de Conteúdo. Lisboa, Portugal; Edições 70, 2009.

11. Ribas V, Dill JS, Cohen PN. Mobility for care workers: Job changes and wages for nurse aides. Soc sci med. 2012;75(12):2183-90. 
12. Montgomery TM. Learning to Lead. Nurs womens health.

2012;16(2): 109-12.

13. Fontana RT, Brigo L. Estudar e trabalhar: percepções de técnicos de enfermagem sobre esta escolha. Esc Anna Nery Rev Enferm. 2012;16(1):128-33.

14. Silva KL, Sena RR, Grillo MJC, Gandra EC, Silveira MR. Expansão dos Cursos de Graduação em Enfermagem: dilemas e contradições frente ao mercado de trabalho. Rev Esc Enferm USP. 2013;47(5):1219-26.

15. Braine Me; Parnell J. Exploring student's perceptions and experience of personal tutors. Nurse educ today.

2011;31(8):904-10.

16. Kraemer FZ, Duarte MLC, Kaiser DE. Autonomia e trabalho do enfermeiro. Rev gaúch enferm. 2011;32(3):487-94.

17. Paula GF, Figueiredo MLF, Camargo FC, Iwamoto HH, Caixeta $\mathrm{CRCB}$. Concepções de liderança entre enfermeiros assistenciais de um hospital do Norte de Minas Gerais. Rev eletrônica enferm. [Internet]. 2012 [Acesso em: 05 Mai 2013];14(4):821-30.

Disponível em:

http://www.revistas.ufg.br/index.php/fen/article/view/15102. 18. Sprandel LIS, Helena Heidtmann Vaghetti HH. Valorização e motivação de enfermeiros na perspectiva da humanização do trabalho nos hospitais. Rev eletrônica enferm. [Internet]. 2012 [Acesso em: 05 Mai 2013];14(4):794-802. Disponível em: http://www.revistas.ufg.br/index.php/fen/article/view/16100/13 343.

Artigo recebido em 10/05/2013.

Aprovado para publicação em 16/06/2014.

Artigo publicado em 31/12/2014. 